\title{
LA PRIMERA GENERACIÓN DE PINTORES NAVARROS CONTEMPORÁNEOS: APORTACIONES PARA UN CATÁLOGO DE SUS PINTURAS EN EL MUSEO DE NAVARRA ${ }^{1}$
}

\author{
POR \\ IGNACIO J. URRICELQUI PACHO \\ Universidad de Návarra
}

Este trabajo desea contribuir a la elaboración de un catálogo de pinturas del Museo de Navarra con el estudio de una serie de obras realizadas a finales del siglo XIX y principios del siglo XX por un grupo de artistas que vienen a constituir la primera generación de pintores contemporáneos de esta región. De un lado ofrecemos la corrección de una serie de datos inexactos detectados en la catalogación de estas pinturas, de otro, aportamos información novedosa que contribuirá a un mejor conocimiento de este interesante conjunto artístico. Igualmente, no escapa a nuestro objetivo, ayudar a una revalorización de la pintura realizada en Navarra durante un período trascendental para la pintura española.

Palabras clave: Museo de Navarra. Depósito. Pintores. Tradición y Modernidad.

This study contributes to the elaboration of a catalogue of paintings in the Museo de Navarra by examining a series of works from the late nineteenth and early twentieth centuries carried out by a group of artists who constituted the first generation of contemporary painters in this region. On the one hand, inexact data has been corrected, and on the other, new information is brought to light which will contribute to a better understanding of this artistic group. Likewise, an attempt is made to revaluate paintings carried out in Navarre during this transcendental period for Spanish painting.

Key words: Museo de Navarra. Deposit. Painters. Tradition \& modernity.

El objetivo de este trabajo es colaborar a la elaboración de un catálogo de pinturas del Museo de Navarra a través del estudio de las obras realizadas por los miembros de la llamada, de un modo ya algo tópico, primera generación de pintores navarros contemporáneos, uniéndonos de esta manera a una serie de trabajos que desde algún tiempo van centrando la atención en los pintores activos en nuestra comunidad a finales del siglo xIx y primeras décadas del $\mathrm{xx}^{2}$. Denomi-

\footnotetext{
1 Este trabajo ha sido posible gracias a una ayuda a la investigación concedida por la Institución Príncipe de Viana del Gobierno de Navarra, Orden Foral 195/2000, de 22 de mayo, del Consejo de Educación y Cultura.

${ }^{2}$ En este sentido hay que destacar, entre otros trabajos los de Martín-Cruz, S. (Dir.), Pintores navarros, 3 t.t., CAMP, Pamplona, 1981; Zubiaur, F. J., La Escuela del Bidasoa, Gobierno de Navarra, Pamplona, 1985; Muruzábal, J. M. ${ }^{\text {.., Ba- }}$ siano, el pintor de Navarra, CAMP, Pamplona, 1989; Manterola, P., y Paredes, C., Arte navarro, 1850-1940, Col. Panorama, núm. 18, Pamplona, 1991; Alegría Goñi, C., El pintor J. Ciga, CAMP, Pamplona, 1992.
} 
namos con este epígrafe a aquellos artistas nacidos entre 1834 y 1875 que, o bien por nacimiento o por estancia, quedan vinculados a Navarra, y que contribuyeron con sus obras a su enriquecimiento artístico. De este modo, quedarían incluidos en la nómina Salustiano Asenjo (Pamplona, 1834-Valencia, 1897), Eduardo Carceller (Valencia, 1844-Pamplona, 1925), Andrés Larraga (Valtierra, 1860-Barcelona, 1931), Inocencio García Asarta (Gastiáin, 1861-Bilbao, 1921), Enrique Zubiri (Valcarlos, 1868-Pamplona, 1943), Ricardo Baroja (Huelva, 1871-Vera de Bidasoa, 1953), y Nicolás Esparza (Tudela, 1873-Sestao, 1928) ${ }^{3}$.

$\mathrm{Al}$ englobarlos en un mismo grupo no queremos presuponer la existencia de una escuela o de un círculo artístico con características comunes a todos ellos, si bien algunos sí las tuvieron, como su formación tradicional a través de la Escuela Especial de Pintura, Escultura y Grabado de Madrid (Eduardo Carceller, Nicolás Esparza y Enrique Zubiri), su labor docente desde centros oficiales (Eduardo Carceller, Enrique Zubiri) o privados (Inocencio García Asarta), o la relación personal entre varios de ellos a través de las tertulias de «La Navarra artística» ${ }^{4}$, aspectos éstos de gran interés para la lenta pero progresiva activación de la vida artística en esa región. Igualmente, algunos de ellos contribuyeron a la entrada de temas y planteamientos compositivos y colorísticos que supusieron una primera toma de contacto con aires modernos. Las obras de estos pintores, a caballo entre los siglos XIX y XX, nos ponen de manifiesto, como acertadamente señala Carmen Alegría, que, pese a sentirse atraídos por los temas históricos, "comienzan a interesarse por el paisaje al aire libre, por el retrato muy en boga entre la incipiente burguesía o por los temas costumbristas» ${ }^{5}$, es decir, por algunas de las modas que imperaban en la España más modernizada del momento desde el punto de vista artístico. No obstante, pese a estas primeras «tomas de contacto», la Navarra finisecular no contaba con los mecanismos necesarios (clientela, crítica, apoyo institucional, etc.) para la formación de un clima favorable, aspecto éste que no llegaría hasta bien entrado el siglo xx, lo que provocó que algunos de estos artistas optaran o bien por buscar mejor suerte en otros centros que garantizaran una demanda (Inocencio García Asarta y Nicolás Esparza en el País Vasco), o bien dedicarse a la labor docente (Eduardo Carceller, Enrique Zubiri, en la Escuela de Artes y Oficios de Pamplona), produciéndose en el primero de los casos una dispersión de las obras, y en el segundo, una considerable reducción de la producción artística ${ }^{6}$.

Para el estudio de estas pinturas contamos, además de con algunas menciones y fichas críticas dispersas en diferentes publicaciones, con la actual guía-catálogo del Museo de Navarra que desde su edición en 1989, en sustitución de una anterior en la que estas pinturas no venían recogidas $^{7}$, ofrece la posibilidad de tomar contacto con ellas ${ }^{8}$, si bien el práctico desconoci-

\footnotetext{
${ }^{3}$ Alegría Goñi, C., «Pintores contemporáneos I», en El arte en Navarra, t. I, Pamplona, 1994, pp. 582-584. Aquí Carmen Alegría Goñi se refiere a este grupo de artistas con el epígrafe de «Maestros de la pintura contemporánea», aludiendo a la importante labor docente que desempeñaron algunos de ellos como Asenjo, Esparza, Zubiri y, durante algún tiempo, García Asarta. Ver también Manterola, P., Voz «Pintura», en Gran Enciclopedia Navarra, Pamplona, C.A.N., 1990, p. 156; Zubiaur, F. J., «Pintura y escultura contemporáneas», III Congreso General de Historia de Navarra, Pamplona, 1994, p. 3 (Ed. CD).

${ }^{4}$ Este nombre fue acuñado por José M. ${ }^{a}$ Muruzábal en alusión a una especie de tertulia que de manera informal se celebraba en el local que Francisco Sánchez Moreno regentaba en la calle Eslava de Pamplona y donde parece ser que habitualmente se daban cita artistas y gentes sensibles a la cultura. Entre los tertulianos se encontraban algunos de nuestros pintores como Inocencio García Asarta y Enrique Zubiri, además de otros de generaciones posteriores como Javier Ciga, Jesús Basiano, Millán Mendía, Crispín Martínez, Julio Briñol, Miguel Pérez Torres, etc., así como artistas con mayor proyección nacional como Ricardo Baroja o Ignacio Zuloaga. Ver Muruzábal, J. M. ${ }^{a}$, Op. cit., p. 34; Alegría Goñi, C., «Pintores contemporáneos I», p. 580; y Martín-Cruz, S., Emilio Sánchez Cayuela «Gutxi», Caja Navarra, Pamplona, 2000, pp. 8 y 9.

${ }^{5}$ Alegría Goñi, C., «Pintores contemporáneos I», p. 582.

${ }^{6}$ Sobre esto, algunas notas en Zubiaur, F. J., 75 años de pintura en Navarra. 1921-1996, Pamplona, 1996, pp. 9-11. Catálogo de la exposición.

${ }^{7}$ Mezquíriz, M. ${ }^{\text {a }}$ A., El Museo de Navarra, Pamplona, 1956. Reediciones en 1963, 1969 y 1978.

${ }^{8}$ AA.VV., Guía-catálogo del Museo de Navarra, Gobierno de Navarra, Pamplona, 1989. Reediciones en 1990,1993 y 1998.
}

$A E A, \mathrm{LXXV}, 2002,300$, pp. 381 a 396 
miento de la vida y producción de los artistas que las produjeron dificulta la acertada comprensión de este interesante conjunto pictórico, que pasamos a analizar a continuación.

\section{Análisis de las obras}

Seguiremos un orden cronológico con relación al autor de la obra, lo que nos permitirá establecer un método más cómodo. Así pues, el primero de los maestros representados es Salustiano Asenjo (1834-1897) ${ }^{9}$. El Museo de Navarra tan sólo posee una obra de este interesante autor ${ }^{10}$, expuesta en la tercera planta y procedente del lote de doce pinturas depositadas por la Diputación de Navarra en el Museo en $1967^{11}$ (Fig. 1). Desgraciadamente, es poco significativa de su producción por tratarse de una copia del lienzo «La Cava saliendo del baño», realizado por el pintor Isidoro Lozano en 1854, durante su segundo año de pensión en Roma, con el que obtuvo una Segunda Medalla en la primera Exposición Nacional de Bellas Artes, celebrada en Madrid en $1856^{12}$.

La pintura, de marcado academicismo y precisa en el dibujo y modelado de las figuras, nos presenta en el centro a una muchacha semidesnuda que se cubre la parte inferior del cuerpo con una túnica blanca con los bordes decorados con una greca. La joven es ayudada a vestirse por una doncella de cabellos oscuros recogidos en dos trenzas que caen sobre los hombros y

\footnotetext{
${ }^{9}$ Sobre Salustiano Asenjo, ver Osorio y Bernard, M., Galería biográfica de artistas españoles del siglo XIX, Madrid, 1975 (1. ${ }^{a}$ ed. 1887); Martín-Cruz, S., «Salustiano Asenjo Arozarena. El retratista de Sarasate», en Pintores navarros, t. I, Pamplona, 1981; Boix, V., Noticia de los artistas valencianos del siglo XIX, Valencia, 1877; Iriarte, J., Biografías de los ilustres navarros del siglo xviII, t. III, Pamplona, 1952; Aldana Fernández, S., Guía abreviada de artistas valencianos, Valencia, 1970; Madariaga, L., Pintores vascos, San Sebastián, 1971; Molins Mugueta, J. L., «El pintor Salustiano Asenjo Arozarena», en Vida Vasca, N..$^{\circ}$ 8, 1981; Buendía, R., Tierras de España. Navarra, Fundación Juan March, Vitoria, 1988; Paredes, C., Arte navarro 1850-1940, Op. cit.; Alegría Goñi, C.: «Pintores contemporáneos I», Op. cit.

10 «La Cava saliendo del baño», óleo/lienzo, 131 x89 cms., N. Reg.: 1367 K. Nótese que en nota 11 este lienzo figura con el título «David y Betsabé», cuestión que se analizará más adelante.

$"$ Museo de Navarra. Archivo y Biblioteca. Registro de entradas, 1967. N. ${ }^{\circ}$ Registro: 1367 K. Forman parte de este lote las siguientes obras: «Cuadro de gitana», (N. ${ }^{\circ}$ Reg: $1367 \mathrm{~B}$ ), «Retrato de niña» (N. ${ }^{\circ}$ Reg.: $1367 \mathrm{C}$ ), «Carro de bueyes» (N. ${ }^{\circ}$ Reg.: 1367 D), «Retrato de la reina María Cristina» (N. ${ }^{\circ}$ Reg.: 1367 E), los cuatro de Inocencio García Asarta; «Guerrero desnudo» (N. ${ }^{\circ}$ Reg.: $1367 \mathrm{~F}$ ) y «Ayudando a la lectura» (N. ${ }^{\circ}$ Reg.: $1367 \mathrm{G}$ ), ambos de Nicolás Esparza; «El Rapapobres» (N. ${ }^{\circ}$ Reg.: $1367 \mathrm{H}$ ), y «El monaguillo» (N. ${ }^{\circ}$ Reg.: 1367 I), de Eduardo Carceller; «David y Betsabé» (N. ${ }^{\circ}$ Reg.: $1367 \mathrm{~K}$ ), de Salustiano Asenjo; «Retrato de dama» (N. ${ }^{\circ}$ Reg.: $1367 \mathrm{~L}$ ), de Julio Briñol; y «Aguadora (La Fornarina)» (N. ${ }^{\circ}$ Reg.: 1367 M) y «Mujer con cesto de frutas» (N. ${ }^{\circ}$ Reg.: 1367 N), ambos de Jesús Basiano. Nótese que entre los cuadros de García Asarta se menciona un «Retrato de la reina María Cristina», que no estudiaremos aquí por encontrarse actualmente en el Palacio de Navarra. Es interesante señalar que en 1917 la Comisión de Monuentos Históricos y Artísticos de Navarra, fundada en 1844, depositó en el Museo Arqueológico de Navarra, creado en 1910 y clausurado en 1940, un lote de obras entre las que figuran algunas de las que ahora vamos a estudiar. Sirvan estos datos para comprender el itinerario que han seguido estas pinturas hasta su actual ubicación en el Museo de Navarra. Sobre la Comisión de Monumentos Históricos y Artísticos de Navarra y este depósito en particular, ver Quintanilla, E., La Comisión de Monumentos Históricos y Artísticos de Navarra, Pamplona, Gobierno de Navarra, 1997, pp. 265-267. En dicho depósito figuraron los siguientes lienzos: «Retrato de Fernando VII», anónimo; «Id. de Isabel II, Niña», anónimo; «Escena de tocado y baño (David y Betsabé?)», Asenjo; «Gitana tocando la guitarra», Asarta; «Estudio de hombre desnudo ( $\sin$ marco)», Asarta; «Estudio de mujer y niña», Esparza; «Estudio de gladiador (sin marco)», Id.; «Estudio de viejo (lienzo sin bastidor ni marco)», Id.; «Marina», Larraga; «Iglesia de pueblo», Basiano; «Composición con la mascarilla de Beethoven», Id.; «Estudio de paisaje y río», Yzangorena; «Retrato de dama (dibujo)», Esparza; El mismo (grabado), Id.; «Retrato del marqués del Vadillo (al carbón)», Echenique; «Retrato de hombre desconocido (Copia de la galería Capitolina)», Martín Miguelazparra (debe tratarse de Martín Miguel Azparren, el autor de las pinturas del techo del Salón del Trono del Palacio de Navarra); «Retrato de la Reina Mercedes (grabado)», sin especificarse el autor. Además se mencionan otros objetos que no vienen al caso.

${ }^{12}$ Isidoro Lozano, «La cava saliendo del baño», óleo sobre lienzo, 212x136 cms. Museo de la Academia de Bellas Artes de San Fernando, Madrid. Ver Castro, A. de, Catálogo del Museo de la Real Academia de Bellas Artes, Madrid, 1929 (1. ${ }^{a}$ ed.), p. 88. Ver también Pérez Sánchez, A., Real Academia de Bellas Artes de San Fernando. Inventario de las pinturas, Madrid, 1964, p. 36. En una reciente publicación con motivo de la exposición La Rioja. Tierra abierta, celebrada en la catedral de Calahorra del 15 de abril al 30 de septiembre de 2000, se indica que el autor es Isidoro Santos, si bien nosotros consideramos que se trata de un error. Ver, Catálogo de la exposición La Rioja. Tierra abierta, Logroño, 2000, p. 81.
}

AEA, LXXV, 2002, 300, pp. 381 a 396 
que viste unas prendas de tonos anaranjados. A la derecha de ambas, sobre una ara de piedra decorada con bajo relieves, en la que se apoya la sirvienta, se depositan los vistosos ropajes de la Cava, de tonos cálidos, amarillos y rojos, decorados con bordados. Al fondo, entre la maleza, y camuflado a la derecha de la pareja, un hombre barbado y con melena ceñida por una diadema dorada observa la escena.

Trảdicionalmente se ha identificado esta escena de Asenjo con el pasaje bíblico de David observando el baño de Betsabé ${ }^{13}$, si bien algunos autores dudaron de tal atribución señalando que el asunto representado correspondía con el de la Cava y el rey don Rodrigo ${ }^{14}$. Ya Salvador Martín Cruz acertó al indicar en 1981 que el asunto del lienzo, considerado entonces inspirado en el episodio bíblico, nos mostraba a unos personajes que «tienen más que ver con la tradición de peinados y ropajes godos que con la judaica» ${ }^{15}$.

La obra de Salustiano Asenjo no viene fechada, y ha sido considerada por la mayoría de la segunda mitad del siglo XIX ${ }^{16}$. Nosotros no podemos aventurarnos a dar una fecha concreta de ejecución, aunque nos inclinamos por señalar que la obra fue ejecutada con posterioridad a 1856, año en el que el lienzo original de Isidoro Lozano fue presentado a la primera Exposición Nacional. El artista navarro debió copiar esta obra en uno de sus viajes a Madrid, en la década de los sesenta o setenta, y en todo caso antes de 1877, año en el que la menciona Vicente Boix en su Noticia de los artistas valencianos del siglo XIX ${ }^{17}$. Por lo tanto, situamos esta obra entre las coordenadas cronológicas de 1856-1877.

Las siguientes pinturas que vamos a analizar corresponden al segundo de los maestros representados en el Museo de Navarra, el valenciano Eduardo Carceller (1844-1925) ${ }^{18}$. El Museo de Navarra posee tres retratos de este artista que se encuentran expuestos en la tercera planta. Los dos primeros, procedentes del depósito realizado en 1967 por la Diputación Foral ${ }^{19}$, fueron regalados por el artista a la Comisión de Monumentos de Navarra, de la cual era vocal, en 1906 y 1917 respectivamente con destino al Museo Arqueológico, activo desde $1910^{20}$.

${ }^{13}$ II Sam, 11, 2

${ }^{14}$ Sobre este particular, ver las opiniones de los diferentes autores: Boix, V., Op. cit., p. 17; Iriarte, J., Op. cit., p. 43; Aldana Fernández, S., Op. cit., p. 35; Madariaga, L., Op. cit., p. 70; Molins Mugueta, J. L., Op. cit.; Buendía, R., Op. cit., p. 308; Paredes, C., Op. cit., p. 42; Alegría Goñi, C., «Pintores contemporáneos I», pp. 582 y 589.

${ }_{15}$ Martín-Cruz, S., «Salustiano Asenjo Arozarena. El retratista de Sarasate», en Pintores navarros, t. I, Pamplona, 1981, p. 13. Carlos Reyero ha estudiado en un excelente trabajo los temas tratados por los pintores de historia del siglo XIX, dedicando un capítulo entero al episodio de la Cava y don Rodrigo. «Rodrigo - Don Rodrigo-, señala el autor, fue, de todos los caracteres de la historia española — no sólo de la medieval-, uno de los que más se prestó, dentro y fuera de nuestras fronteras, a la imaginación romántica.», ver Reyero, C., Imagen histórica de España (1850-1900), Madrid, 1987, p. 58. En otra parte señala el mismo autor que sólo el tema de la Cava escapó por su pintoresquismo de la grandilocuencia de contenidos de la pintura de historia del siglo XıX en España. A este respecto ver Reyero, C., «Los temas históricos en la pintura española del siglo XIX», en AA.VV.: La pintura de historia del siglo XIX en España, Madrid, 1992, p. 42. Catálogo de la exposición. Ver también, del mismo autor, La pintura de historia en España, Cátedra, Madrid, 1989, pp. 171-172.

${ }^{16}$ La guía-catálogo del Museo de Navarra fecha la obra en la segunda mitad del siglo xix. De igual modo se posiciona Carmen Alegría, mientras que Camino Paredes la sitúa entre 1860 y 1897. Ver, AA.VV., Guía-catálogo del Museo de Navarra, Op. cit., p. 203; Alegría Goñi, C., «Pintores contemporáneos I», p. 589; PAREDES, C., Op. cit., p. 42.

${ }^{17}$ Boix, V., Op. cit., p. 17. Aquí el autor señala que la obra se conserva en la Diputación de Navarra «la cual le brindó con la pensión a Roma», si bien no hemos podido confirmar el dato. Molins Mugueta, en el artículo citado (ver nota 9) señala en cambio que durante su etapa de formación juvenil realizó frecuentes viajes a Italia. Por su parte el Barón de Alcahalí coincide en la noticia de la pensión, si bien señala que el artista la rehusó «por no abandonar su cátedra» en la Escuela de Bellas Artes de Valencia, Alcahalí, B., Diccionario biográfico de artistas valencianos, Imprenta de F. Doménech, Valencia, 1897 , p. 54.

${ }^{18}$ Paredes, C., Op. cit.; Alegría Goñi, C., «Pintores contemporáneos I», Op. cit.

${ }^{19}$ Ver nota 11.

${ }^{20}$ «El Rapa-pobres», 1870, óleo/lienzo, 45’5 × 36 cms, N. Reg.: 1367 H; y «El monaguillo», 1871, óleo/lienzo, 45’5 × 36 cms., N. Reg.: 1367 I. Ambas fueron regaladas por el propio artista a la Comisión de Monumentos Históricos y Artísticos de Navarra para que formaran parte del Museo Arqueológico, que como ya se ha indicado, abrió sus puertas en 1910. Ver Institución Príncipe de Viana, Archivo: Carta del Vicepresidente de la Comisión de Monumentos al Sr, D. Eduardo Carceller, Pamplona, 18 de octubre de 1906, Comisión de Monumentos, 1906, Legajo 1 - Bis, N. ${ }^{2} 3$; Comisión de Monumentos, Actas, sesión de 30 de junio de 1917. Documentos citados por Quintanilla, E., Op. cit., p. 265.

$A E A, \mathrm{LXXV}, 2002,300$, pp. 381 a 396 

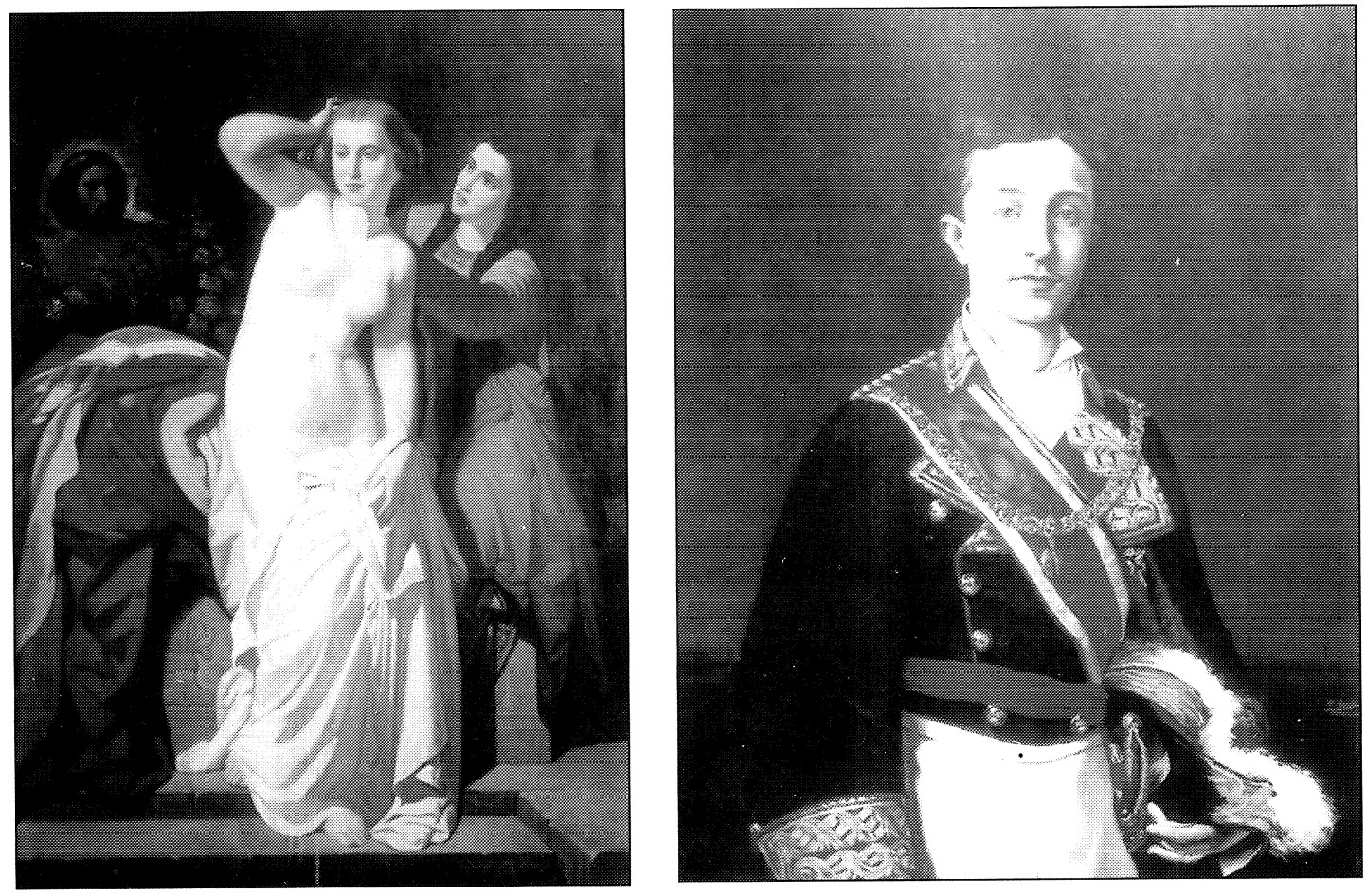

3

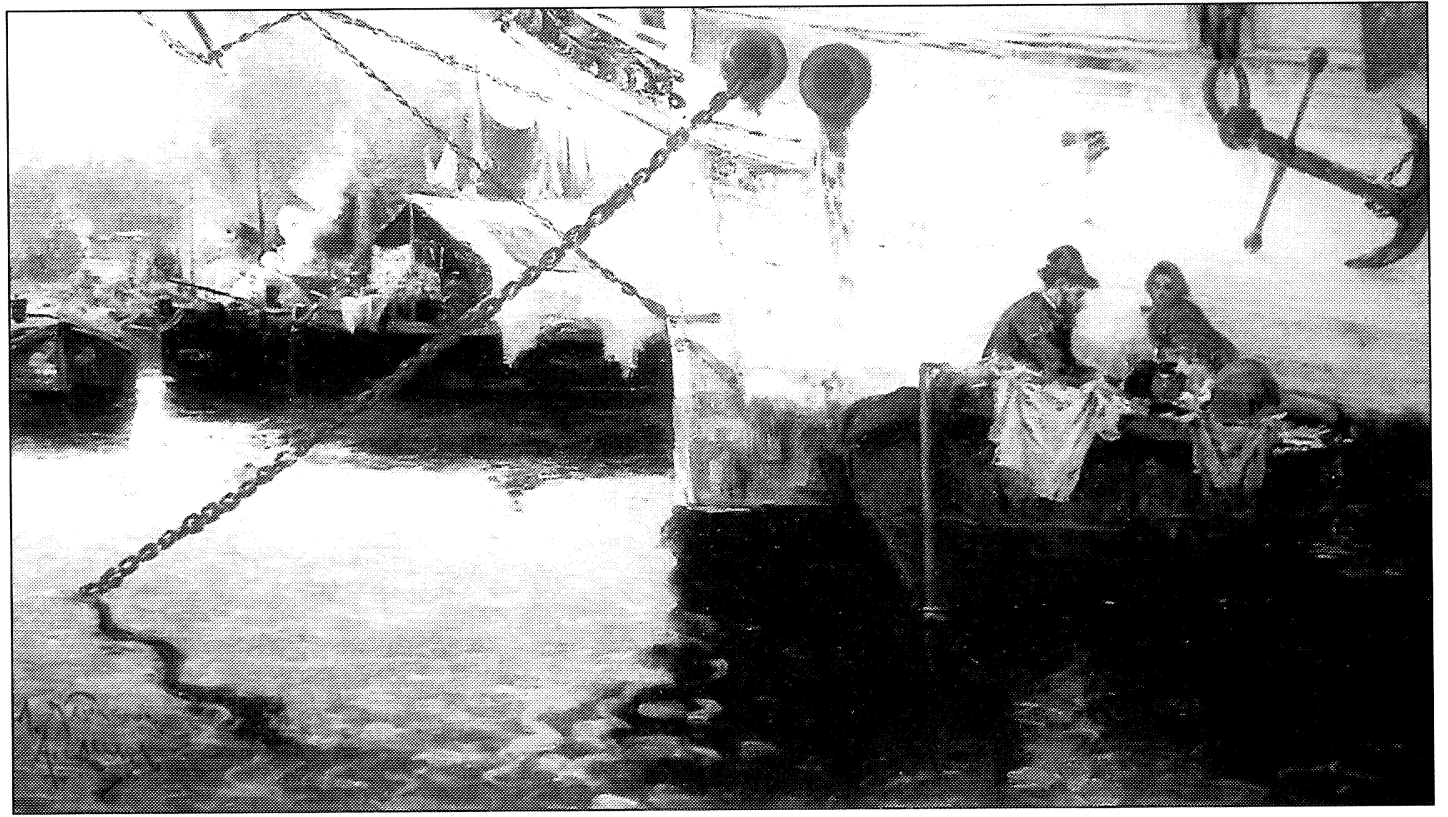

Fig. 1. Salustiano Asenjo, La Cava saliendo del baño, c.a. 1856-1877.

Fig. 2. Eduardo Carceller, Retrato de Alfonso XII, 1878.

Fig. 3. Andrés Larraga, Puerto, c.a. 1890-1900.

AEA, LXXV, 2002, 300, pp. 381 a 396 
Pertenecen a lo que podríamos denominar «retratos costumbristas», esto es, de personajes típicos o pintorescos de una región, en este caso de la ciudad de Tudela (Navarra), en la que el artista vivió de 1870 a 1874 . El primero de ellos representa al Rapa-pobres, nombre con el que se conocía al asalariado de la casa de la Misericordia de la ciudad ribera que, ataviado con una banda de cuero blanco cruzada al pecho y armado con una espada de madera, se encargaba de evitar la mendicidad por las calles ${ }^{21}$. Por su parte, el otro busto representa a un monaguillo de la seo tudelana ataviado con las vestimentas propias de los Infantes de coro: sotana con sobrecuello, roquete y lazo. Ambos van acompañados de un texto en la parte superior que nos ayuda a identificar a los retratados — «Rapa-pobres» en el primero y «Remijan» en el segundo, procedimiento habitual en la época y que veremos repetido en el retrato de Martín Azpilicueta realizado por Enrique Zubiri.

Los dos bustos, firmados y fechados en el ángulo superior izquierdo en 1870 y 1871 respectivamente $^{22}$, dejan clara la influencia velazqueña en la obra de Eduardo Carceller, en especial a través de los acertados tonos encarnados de los rostros y de la iluminación dorada que incide sobre ellos. Creemos que ambas pinturas forman parte de una serie de lienzos que Carceller debió realizar durante sus primeros años en Tudela, impresionado por la particular vida de la ciudad ribera, tan diferente de su Valencia natal, y en los que plasmaría los tipos corrientes de la localidad, entre los que tienen cabida los personajes pintorescos, algo excéntricos, como el Rapa-pobres, y aquellos más cotidianos, como el joven monaguillo que ayuda en los oficios diarios.

Como ya hemos señalado, el Museo de Navarra posee una tercera obra de este artista. Se trata de un retrato de Alfonso XII ${ }^{23}$ (Fig. 2). Eduardo Carceller lo retrata en sus años jóvenes, apuesto y altivo, vestido con casaca, y banda cruzada al pecho donde se muestran orgullosamente el Toisón de Oro y la Medalla de Carlos III, signos de la autoridad monárquica. Lleva fajín, espada ceñida al cinto y sujeto en la mano izquierda el bicornio, símbolos de su jerarquía militar. Un armonioso fondo de ocres y marrones sirve para resaltar su figura. Llama de nuevo la atención la precisa caracterización del retratado, con un cuidado dibujo, que se hace exquisito en los detalles de los ropajes. El joven monarca es presentado de manera sobria, sin acentuarse en él la soberbia que presenta en otros retratos como el anónimo que conserva el Museo de Bellas Artes de Bilbao, en el que se centra más la atención en su faceta de monarca por encima de la humana, más presente en el retrato del Museo de Navarra ${ }^{24}$.

Pese a que algunas publicaciones datan la obra en $1875^{25}$, está fechada en la parte inferior del margen derecho, junto a la firma, en 1878, año en el que, recordemos, el monarca contrajo matrimonio con su prima Mercedes de Orleans, hija de los Duques de Montpensier, la cual falleció a los pocos meses. Junto a la firma y la fecha podemos leer «Valencia», dato que nos da que pensar sobre si la obra pudo realizarse en la ciudad levantina, en alguno de los viajes que el artista realizara a su tierra natal. En 1878 Eduardo Carceller se encontraba en Pamplona como profesor de Dibujo y Figura de adorno de la Escuela de Artes y Oficios, cargo que obtu-

\footnotetext{
${ }^{21}$ El dato nos lo aporta José María Iribarren en su ya clásico Vocabulario navarro donde además nos informa de que el cargo se creó en 1855, si bien fue suprimido al poco tiempo «a consecuencia de haber golpeado el rapapobres a un mendigo con la espada de madera.» Iribarren, J. M. a., Vocabulario navarro, Pamplona, 1997 (1. ${ }^{\text {a }}$ ed. 1955), p. 429.

${ }^{22}$ La Guía-catálogo del Museo de Navarra coincide en esa fecha. Ver ed. Pamplona, 1998, p. 207. Iribarren en su explicación sobre el término «Rapapobres» menciona el lienzo de Carceller, que él fecha a finales del siglo XIX, e indica que se encontraba por aquel entonces, 1955, depositado en el sótano del Archivo Provincial. Este dato nos ayuda a conocer un poco mejor el complicado itinerario que siguió en lienzo hasta llegar en 1967 a su actual ubicación en el Museo de Navarra.

${ }^{23}$ «Retrato de Alfonso XII», 1878, óleo sobre lienzo, $128 \times 108 \mathrm{cms}$., N. ${ }^{\circ}$ Reg.: 3223 . Se desconoce su fecha exacta de ingreso pero parece ser que para 1993 ya estaba colgada en la tercera planta del museo. Ver ficha de la obra, Museo de Navarra, Archivo y Biblioteca, ficha N. ${ }^{\circ} 3223$.

${ }^{24}$ Anónimo (Copia de Barroeta), «Retrato del rey Alfonso XII», óleo/lienzo, $123 \times 90{ }^{`} 5$ cm., N. ${ }^{\circ}$ de Inv.: 82/2410. Museo de Bellas Artes de Bilbao.

${ }^{25}$ AA.VV., Guía-catálogo del Museo de Navarra, Op. cit., p. 207.
}

AEA, LXXV, 2002, 300, pp. 381 a 396 
vo por oposiciones verificables en 1874. El hecho de que la obra se feche en 1878 en Valencia, arroja nuevos datos sobre la mal conocida biografía de este artista, el cual pudo trasladarse allí en ese año, quizá por motivos familiares.

Toca el turno al autor del que más obras se tienen en el Museo de Navarra, Andrés Larraga Montaner (1860-1931) ${ }^{26}$, quien supo abrirse un hueco dentro de la importante nómina de paisajistas catalanes del momento. Son un total de diez obras las que se conservan en el museo, si bien nueve de ellas se encuentran depositadas en el almacén y sólo una expuesta en la actualidad. Prima en ellas la temática marina, presente en siete de las diez. De todas ellas destaca la titulada «Puerto» ${ }^{27}$ (Fig. 3), ingresada en 1992 procedente del Palacio de Diputación y actualmente expuesta en la tercera planta, en la que el artista refleja de forma magistral el ambiente portuario a través de una composición muy habitual en él, formada por el contraste de espacios de masa y espacios abiertos en profundidad, con el que en este caso consigue de un lado centrar la atención del espectador en la pareja que se encuentra en la barca, posiblemente su único hogar, y de otro lado abrir a la izquierda una vista por la que acertamos a ver el ambiente portuario envuelto por la atmósfera humedecida de las primeras horas de la mañana. Pese a no venir fechada, creemos que puede situarse en torno a 1900, año en el que realiza otro «Puerto», localizado en el almacén, con el que mantiene evidentes similitudes tanto compositivas como estilísticas. Esta pintura nos muestra una vista de un pueblo costero desde una terraza cubierta por un toldo, en la que una mujer, vestida de rosa y con un libro entre las manos, dirige su mirada hacia un punto que escapa a los límites del cuadro ${ }^{28}$. En el almacén se conserva una tercera vista marítima, algo más pobre que estas dos, si bien un tratamiento de restauración le devolvería interesantes calidades cromáticas, en la que la terraza queda sustituida por el saliente de una calle que da al mar, donde un hombre, con un botijo al lado, mira hacia la lejanía ${ }^{29}$. Estas dos vistas marítimas se pueden poner en relación directa con otras del artista en las que se repiten algunas de sus constantes compositivas y técnicas, tales como las figuras que observan las aguas desde un emplazamiento elevado (una terraza, el saliente de una calle, un muelle de madera, un puente, etc.); el fondo montañoso difuminado por la bruma costera y que desciende hasta unirse con el mar en un saliente; las embarcaciones faenando en el mar con las velas desplegadas; el juego de masas a un lado (sean naturales, como una montaña, o artificiales, como una edificación o un barco), y el paisaje (sea terrestre, marítimo, fluvial, etc.) al otro; etc. Dentro de esta línea se encuentran los cuatro apuntes al óleo sobre madera que ingresaron en el Museo en 1998 a través de legado testamentario y que pese a no venir firmados, parece no haber dudas que fueron realizados por el autor navarro ${ }^{30}$.

Muy acorde con la temática marina se encuentra el lienzo titulado «Pecera» ${ }^{31}$. Representa

${ }^{26}$ Rafols, J. F., Diccionario Biográfico de Artistas de Cataluña desde la época romana hasta nuestro días, Barcelona, 1953; Martín Valls, M., Andrés Larraga Montaner (1861- 1931), Pamplona, 1991, catálogo de la exposición; Alegría Goñi, C., «Pintores contemporáneos I», Op. cit.; Paredes, C., Op. cit. Paredes, C. y Díaz, G.: Andrés Larraga, Pamplona, C. C., 2002, Catálogo de la Exposición.

${ }^{27}$ «Puerto (I)», c.a. 1890-1900, óleo sobre lienzo, $70 \times 110$ cms., N. ${ }^{\circ}$ Reg.: 2508. Museo de Navarra, Archivo y Biblioteca, Registro de entradas, 1992 , N. ${ }^{\circ}$ Reg.: 2508.

${ }^{28}$ «Puerto (II)», 1900, óleo sobre lienzo, $75 \times 150 \mathrm{cms}$., N N. ${ }^{\circ}$ Reg.: 3452 . Esta obra procede de un legado testamentario efectuado por una particular en 1998, formado por dos lienzos y cuatro apuntes sobre tabla de Andrés Larraga, y tres lienzos más de Lluis Flotats, Claudio Lorenzale, y Soler. Ver Museo de Navarra, Archivo y Biblioteca, Registro de entradas, 1998, N. ${ }^{\circ}$ Reg.: 3452 y ss.

${ }^{29}$ «Puerto (III)», c.a. 1900, óleo sobre lienzo, $40 \times 70 \mathrm{cms}$., N. ${ }^{\circ}$ Reg.: 3453 . Procede del mismo legado que el anterior

${ }^{30}$ «Barcas atracadas», c.a. 1900 , óleo sobre tabla, $19 \times 32,5$ cms., N. ${ }^{\circ}$ Reg.: 3454 ; «Paisaje», c.a. 1900, óleo sobre tabla, $19,5 \times 32,5$ cms., N. ${ }^{\circ}$ Reg.: 3455 ; «Barca atracada con personaje», c.a. 1900 , óleo sobre tabla, $19,5 \times 32,5$ cms., N. ${ }^{\circ}$ Reg.: 3456; y «Barcos fondeados», c.a. 1900 , oleo sobre tabla, $19 \times 32,5$ cms., N. ${ }^{\circ}$ Reg.: 3457 . Sobre su ingreso en el museo, ver nota 28 .

31 «Pecera», c.a. 1890-1900, óleo sobre lienzo, $54 \times 45$ cms., N. ${ }^{\circ}$ Reg.: 2136 . Ingresó en el museo en 1987 junto a otra obra de Larraga, titulada «Gitana», y a una Inmaculada Concepción del siglo xviI realizada por el corellano Antonio González Ruiz. Ver Museo de Navarra, Archivo y Biblioteca, Registro de entradas, 1987, N. ${ }^{\circ}$ Reg.: 2136. 
un tema submarino en el que vemos un pulpo semioculto entre unas rocas atrapando a un pez de tonos rosados mientras otros dos logran escapar de entre sus tentáculos. Es un tema curioso que reproduce mediante tonos apagados, donde predominan las gamas verdosas, el fondo acuático, y que podemos poner en relación con la tradición marítima mediterránea. Existen pinturas de este tipo, ya en el siglo xx, en la producción de Anglada Camarasa, que llevó al lienzo en repetidas ocasiones la iconografía del Gallo de San Pedro, pez típico de la bahía de Polença ${ }^{32}$. Pese a la extrañeza del tema, Inocencio García Asarta también lo trató al menos en dos obras de formato circular que se encuentran en colección particular, en las que aparecen representados dos espléndidos fondos marinos ${ }^{33}$. Ambas obras se encuentran, a diferencia de la de Larraga, íntimamente relacionadas con el tema de la pesca ya que en una atrevida composición en contra picado nos muestran la parte inferior de una embarcación por la que asoman las siluetas de los afanados pescadores. Desconocemos la fecha de ejecución de la obra de Larraga, si bien creemos que por motivos estilísticos puede situarse en la última década del siglo XIX.

Finalmente, para acabar con este interesante autor, toca hablar de dos lienzos en los que se aborda el género costumbrista. Se trata de las obras tituladas «Gitana»y «Andaluza» ${ }^{34}$. Ambas representan a dos muchachas que nos observan coquetamente desde el soporte. La primera, que adopta una grácil pose de baile, está resuelta a base de ocres, y parece más ajustada en el dibujo y más precisa en los detalles, especialmente en las perlas que recubren su vestido y las que se enroscan en su antebrazo izquierdo. Por su parte, la titulada «Andaluza», dominada por los tonos rojos y asalmonados, muestra una técnica más suelta y abocetada. Acomodándonos a una evolución lógica de su pintura, creemos que la titulada «Gitana» es obra de su primera época, quizá cercana a la década de 1880-1890, donde se mantiene aún firme la lección académica, mientras que la otra parece ser obra más evolucionada en el sentido del color y más cercana a obras posteriores, quizá ya del siglo xx, aunque sin llegar a la riqueza cromática que caracterizará sus pinturas costumbristas de la etapa de madurez ${ }^{35}$.

A continuación le toca el turno a Inocencio García Asarta (1861-1921) ${ }^{36}$, de quien se cuenta con nueve obras, ocho expuestas en la tercera planta y una depositada en el almacén del museo, y quien sin duda es el artista mejor representado de los que estamos estudiando, no sólo por la cantidad de obras expuestas respecto al resto de autores y por la calidad de las mismas, a través de las cuales podemos apreciar su evolución a lo largo de las diferentes etapas, sino sobre todo por la variedad temática, donde tienen cabida retratos, escenas costumbristas y pintura de historia ${ }^{37}$. Tradicionalmente ha sido su faceta como retratista la más destacada por los autores, hasta el punto de que alguno lo ha definido como «heredero de Barroeta» y, más aún, «pintor oficial de Bilbao» ${ }^{38}$, si bien tales calificativos deberían ser matizados. In-

\footnotetext{
${ }^{32}$ AA.VV., A la playa. El mar como tema de la modernidad en la pintura española, 1870-1936, Fundación Cultural Mapfre Vida, Madrid, 2000, pp. 288-291.

${ }^{33}$ Inocencio García Asarta, «Fondo submarino I» y «Fondo submarino II», c.a. 1911-1921, óleo sobre lienzo, 36,5 cms. de diámetro. Colección particular (Navarra).

${ }^{34}$ «Gitana», c.a. 1880-1890, óleo sobre lienzo, $69 \times 52$ cms., N. ${ }^{\circ}$ Reg.: 2135; «Andaluza», c.a. 1900, óleo sobre tabla, $47 \times 72 \mathrm{cms}$. N. ${ }^{\circ}$ Reg.: 1613. Nótese que la guía-catálogo del Museo de Navarra señala que el soporte de esta obra es lienzo cuando en realidad es tabla, ver AA.VV., Guía-catálogo del Museo de Navarra, Op. cit., p. 194. Sobre el ingreso de la primera ver nota 31; la segunda fue adquirida por el museo en 1978, ver Registro de entradas, 1978, N. $^{\circ}$ Reg.: 1613.

${ }^{35}$ AA.VV., Guía-catálogo del Museo de Navarra, Op. cit., p. 194. Aquí se indica que es obra de finales del xix.

${ }^{36}$ Suescun, J., «Inocencio García Asarta. Una trayectoria que empieza en Roma y París», en Martín-Cruz, S. (Dir.), Pintores navarros, t. I, Pamplona, 1981; Arozarena, I., Inocencio García Asarta, Pamplona, 1991, catálogo de la exposición; y especialmente, Urricelqui, I. J., La recuperación de un pintor navarro: Inocencio García Asarta (1861-1921), inédito.

${ }^{37}$ Sobre estas pinturas ver nuestro trabajo, Urricelqui, I. J., «Inocencio García Asarta en el Museo de Navarra», en Príncipe de Viana, n. 225, enero-abril 2002.

${ }^{38}$ Llano Gorostiza, M., Pintura vasca, Bilbao, 1965, p. 240. Hacemos notar que García Asarta vivió en la capital vizcaína desde 1898 hasta 1921 , año de su fallecimiento.
}

$A E A, \mathrm{LXXV}, 2002,300$, pp. 381 a 396 


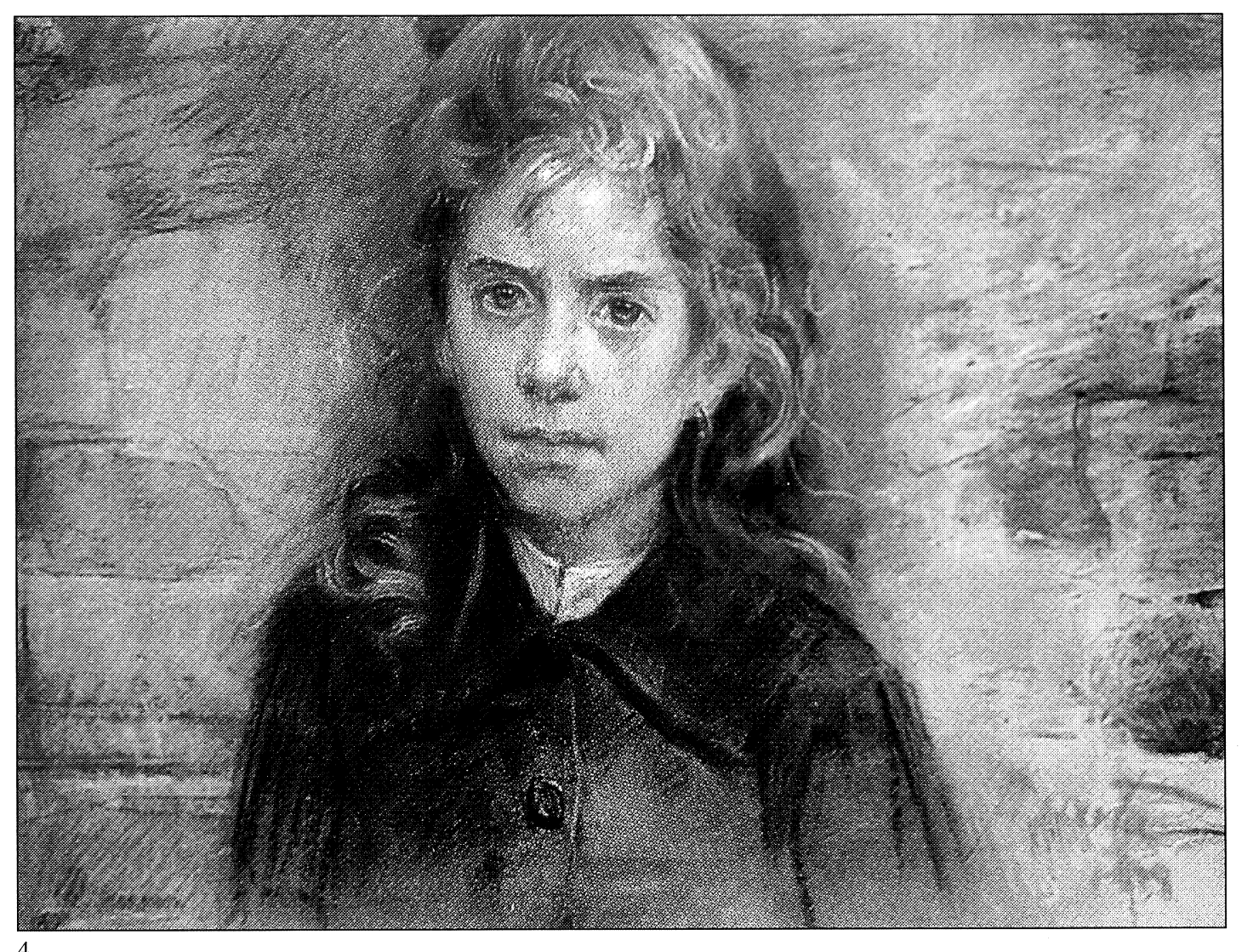

4

5

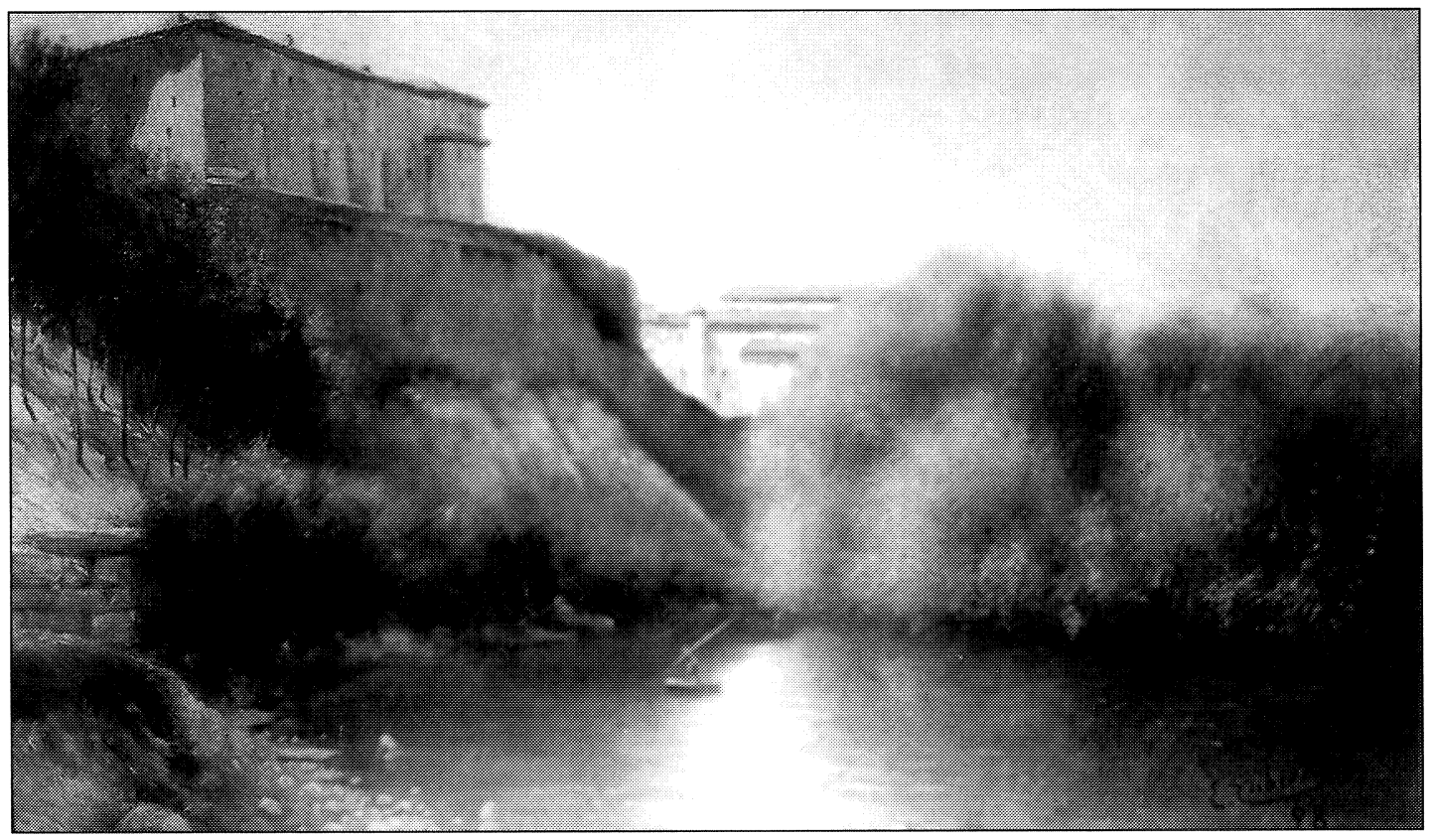

Fig. 4. Inocencio García Asarta, Retrato de niña, 1898.

Fig. 5. Enrique Zubiri, Vista de Pamplona, 1898.

AEA, LXXV, 2002, 300, pp. 381 a 396 
dudablemente, retratos como el del niño Alejandro Olazarán ${ }^{39}$, realizado en 1896, el retrato de mujer ${ }^{40}$, que nosotros creemos cercano a 1905 si ponemos el tipo físico de la retratada en relación con algunas pinturas de ese período como «Maternidad» ${ }^{41}$, del Museo de Bellas Artes de Bilbao, o la cabeza de pastorcillo ${ }^{42}$ que se conserva en el almacén, de hacia 1900, nos muestran a un artista perfectamente dotado para superar las dificultades que el género requiere. De todos lo retratos que cuelgan de las paredes del Museo de Navarra nos quedamos con el magistral retrato de niña, procedente del depósito de 1967 y que fue donado por el propio artista a la Comisión de Monumentos Históricos y Artísticos en 1907 para que formara parte del Museo Arqueológico ${ }^{43}$ (Fig. 4). En esta obra, fechada en el ángulo inferior derecho en $1898^{44}$ y que creemos se puede poner en relación con otras obras como «Niños», del Museo de Bellas Artes de Bilbao ${ }^{45}$, en las que se trata el tema de la infancia, García Asarta ha logrado ir más allá de la simple representación de un rostro, entrando en la misma sicología de la niña, que nos observa con mirada lánguida y enfermiza ${ }^{46}$.

No nos olvidamos de otro interesante retrato, realizado a la acuarela, técnica con la que García Asarta supo poner sello de personalidad ${ }^{47}$, que representa a su amigo Hilario Olazarán, tal y como nos señala la dedicatoria situada en la parte inferior derecha ${ }^{48}$. El retratado aparece de frente, con los brazos cruzados sobre una mesa, vestido de traje azul y corbata, recortado sobre un fondo resuelto a base de manchas donde predominan los ocres y azules de diferentes tonalidades. Esta pequeña obra nos acerca a la interesante faceta de la no-oficialidad, donde García Asarta logró liberarse de las ataduras de la clientela y dedicarse a un arte más íntimo y colorista ${ }^{49}$.

Decíamos que al artista se le ha considerado bajo la perspectiva de retratista, si bien es en el campo de la pintura de costumbres donde alcanza sus mejores obras. El Museo de Navarra cuenta con un interesante cuadro titulado «Gitana con guitarra» procedente del depósito de $1967{ }^{50}$. La obra está dedicada «a la Excm. ${ }^{a}$ Dcion. de Navarra», lo que ha llevado a señalar a algunos autores en diferentes publicaciones que este fue el cuadro que acompañó la instancia

39 «Retrato del niño Alejandro Olazarán», óleo/tabla, $27 \times 35$ cms., N. ${ }^{\circ}$ de Reg.: 1444. Fue cedido en depósito al museo en 1970 junto al retrato de don Hilario Olazarán, también de García Asarta, ver Registro de entradas, 1970, y Memoria del Museo de Navarra, 1970, p. 5.

40 «Retrato femenino», óleo/lienzo, $46 \times 41 \mathrm{cms}$., N. ${ }^{\circ}$ de Reg.: 1516 . Adquirido por el museo en 1975, ver Registro de entradas, 1975 , N. ${ }^{\circ}$ Reg.: 1516.

${ }^{41}$ «Maternidad», óleo sobre lienzo, 80’3 × 60’5 cms., N. ${ }^{\circ}$ Inv.: 82/938. Museo de Bellas Artes de Bilbao.

42 «Cabeza de pastorcillo», óleo sobre lienzo, $32 \times 24 \mathrm{cms}$., N. ${ }^{\circ}$ Reg.: 2142 . Fue adquirido en 1988 junto a tres lienzos de Jesús Basiano. Ver Registro de entradas, 1988, N. ${ }^{\circ}$ Reg.: 2142.

${ }^{43}$ «Retrato de niña», pastel, $45^{\prime} 5 \times 60 \mathrm{cms}$., N. ${ }^{\circ}$ de Reg.: 1367 C. Institución Príncipe de Viana, Archivo, Comisión de Monumentos, Actas, sesión de 30 de octubre de 1907. En dicho documento no se especifica el asunto de la obra, sino únicamente la técnica empleada, no obstante, somos de la opinión de Emilio Quintanilla de identificar dicho pastel con el que ahora se exhibe en el Museo de Navarra con el título de «Retrato de niña». Ver Quintanilla, E.: Op. cit., p. 273, nota 104. Ver además nuestra nota 11 .

${ }^{44}$ Los autores no se han puesto de acuerdo para datar la obra. Así, Martín-Cruz la fechó en 1919, mientras que la guíacatálogo del Museo de Navarra la data en 1895, fecha que también es aceptada por Carmen Alegría Goñi, quien es consciente de que el estilo de la misma corresponde más a su época parisina que a su etapa de vejez. Nosotros sin embargo, nos atenemos a la fecha que aparece en rojo en el ángulo inferior derecho de la obra, junto a la firma, donde creemos ver 1898. Martín-Cruz, S., «Retrato de niña», en Diario de Navarra, 7 de febrero de 1991; AA.VV., Guía-catálogo del Museo de Navarra, Pamplona, 1998 (4. a ed.), p. 204; Alegría Goñi, C., «Pintores contemporáneos I», p. 589.

45 «Niños», 1899, óleo sobre lienzo, $17,5 \times 24,3$ cms., N. ${ }^{\circ}$ Inv.: 82/2466. Museo de Bellas Artes de Bilbao

46 «Retrato de niña» del Museo de Navarra ha sido considerada por los críticos como una de las obras de mayor calidad realizadas por el artista. Ver al respecto Martín-Cruz, S., art. cit.; Alegría Goñi, C., «Pintores contemporáneos I», p. 589 ; Suescun, J., Op. cit., p. 83. Algunas notas sobre la imagen del niño en la pintura se dan en AA.VV., El niño en el Museo del Prado, Ministerio de Cultura, Madrid, 1983.

${ }^{47}$ Marrodán, M. A., Panorama de la acuarela vasca, Bilbao, 1988, p. 51.

48 «Retrato de don Hilario Olazarán», acuarela, $24 \times 21$ ' 5 cms., N. ${ }^{\circ}$ de Reg.: 1445 . Sobre su ingreso, ver nota 39.

${ }^{49}$ Arozarena, I., Op. cit.

${ }^{50}$ «Gitana con guitarra», 1892, óleo sobre lienzo, $64 \times 51$ cms., N. Reg.: 1367 B. Sobre ingreso, ver nota 11.

AEA, LXXV, 2002, 300, pp. 381 a 396 
enviada por García Asarta desde Roma en 1883 solicitando a la Diputación una ayuda económica para continuar sus estudios en dicha ciudad, hecho que está documentalmente demostrado ${ }^{51}$. Esta cuestión ha sido objeto de un reciente estudio que hemos elaborado, en el que argumentamos, con pruebas documentales, que el lienzo «Gitana con guitarra» que ahora analizamos no es el que acompañó dicha instancia de 1883 , ya que esta obra fue ejecutada en 1892, tal y como aparece señalado en el ángulo inferior derecho, junto a la firma y a la dedicatoria, y por lo tanto, no corresponde a su etapa romana (1882-1884), sino a su etapa parisina $(1891-1896)^{52}$. Su estilo es correcto, con un ajustado dibujo que demuestra las evidentes aptitudes del artista, si bien, lo que más nos interesa es el modo en que ha sido aplicado el color, más concretado en la figura y los objetos de primer término, y más suelto en el fondo, llegando incluso a la simple mancha, lo que nos pone de manifiesto su educación parisina, a partir de la cual su pintura se volvió más ágil y colorista ${ }^{53}$.

Dentro de esta faceta costumbrista encontramos otro interesante cuadro titulado «Yunta de bueyes» ${ }^{54} \mathrm{y}$ que es copia de otro del pintor francés Constant Troyon titulado «Beoufs se rendant au labour», actualmente en el Museo D'Orsay, y que el pintor navarro debió realizar observando la obra en el Museo del Louvre, su anterior ubicación, durante su estancia en París entre 1891 y $18966^{55}$. El cuadro figura en varias publicaciones como «Carro tirado por bueyes» ${ }^{56}$, de hecho, apareció con este título en la exposición celebrada en el Museo de Navarra en 1991, suscitando la sorpresa del público que por más buscar no encontraba el referido carro ${ }^{57}$. Su título correcto es «Yunta de bueyes» o más bien, si nos atenemos a la obra original, «Bueyes regresando del trabajo», título genérico que Troyon dio a algunos de sus lienzos. Está fechada en 1893 en el ángulo inferior derecho, si bien su datación no ha quedado clara para los diferentes autores ${ }^{58}$.

Finalmente, toca ocuparnos de «La Batalla de las Navas de Tolosa» y de su boceto en grisalla, ambos cedidos en depósito permanente en 1990 por el Museo de Bellas Artes de Bilbao ${ }^{59}$, y que supone una incursión del artista en el género histórico, que repetirá en otras obras como «Alzamiento del primer rey navarro sobre el pavés», cuadro realizado en 1907 y expuesto en el Ayuntamiento de Pamplona ${ }^{60}$. No resulta extraño que el artista trate en un lienzo este episodio, que junto con las batallas de Roncesvalles y de Olast, marca uno de los episodios más sobresa-

\footnotetext{
${ }^{51}$ Suescun, J., Op. cit., p. 84.

${ }^{52}$ En dicho estudio señalamos que el lienzo que acompañó tal instancia fue una copia del «Entierro de Cristo» de Caravaggio que García Asarta debió de realizar en la Pinacoteca vaticana durante su primer año en Roma. «Gitana con guitarra» presumiblemente fue enviado desde París como regalo a la Diputación en agradecimiento del artista por la pensión recibida durante 1892. Ver Urricelqui, I. J. «Revisión de un lienzo de Inocencio García Asarta», en Príncipe de Viana, núm. 222, enero-abril 2001, pp. 57-74.

${ }^{53}$ Arozarena, I., Op. cit.

${ }^{54}$ «Yunta de bueyes», 1893, óleo sobre lienzo, $158 \times 235$ cms., N. ${ }^{\circ}$ Reg.: 1367 D. Museo de Navarra, tercera planta. Sobre ingreso, ver nota 11.

${ }^{55}$ Martín-Cruz, S., «El carro no se perdió», en Diario de Navarra, 31 de septiembre de 1991. Ver también Les plus beaux tableaux du Louvre, París, 1929, p. 150.

${ }^{56}$ Arozarena, I., Op. cit.

${ }^{57}$ Marco, J., «¿En el Museo de Navarra se ha perdido un carro?», en Diario de Navarra, 22 de septiembre de 1991.

${ }^{58}$ Rogelio Buendía señala que es obra de 1899 , indicando igualmente que el artista viajó a París con una pensión de la Diputación Foral de Álava, algo que no nos parece probable. Por su parte, la guía-catálogo del Museo de Navarra señala que fue realizada en 1893, acogiéndose al año que aparece junto a la firma en el ángulo inferior derecho, dato que nosotros también seguimos. Ver al respecto Buendía, R., Op. cit., p. 309. AA.VV., Guía-catálogo del Museo de Navarra, Pamplona, 1998 (4. ${ }^{\text {a }}$ ed,), p. 206.

${ }^{59}$ «La Batalla de las Navas de Tolosa», óleo/lienzo, 90x134’5 cms., N. ${ }^{\circ}$ de Reg.: 2231 a; «La Batalla de las Navas de Tolosa (boceto en grisalla)», óleo/lienzo, 32'5x45 cms., N. ${ }^{\circ}$ de Reg.: 2231 b. Sobre el procedimiento seguido en la cesión de las obras por parte del Museo de Bellas Artes de Bilbao, ver Galilea Antón, A., «A propósito de las obras del Museo de Bellas Artes de Bilbao depositadas en otras instituciones», en Urtekaria/Anuario 1992, Bilbao, 1993, pp. $51-52,61$ y 67.

${ }^{60}$ «Alzamiento del primer rey de Navarra sobre el pavés», 1907, óleo sobre lienzo, 148x99 cms. Ayuntamiento de Pamplona.
}

AEA, LXXV, 2002, 300, pp. 381 a 396 
lientes del antiguo Reino de Navarra, representando el momento en que el monarca navarro Sancho el Fuerte, cabalgando sobre su caballo, vestido con armadura y con la espada en alto, rompe el cerco que rodea la tienda del caudillo árabe, situada a la derecha, al mismo tiempo que éste se apresura a montar a caballo, ayudado por sus hombres, dispuesto a huir, y a llevarse consigo el mítico pendón que un moro se apresura a recoger. Como acertadamente señaló Carlos Reyero, la Batalla de las Navas de Tolosa «es uno de los temas más genuinamente españoles en la medida que encarna la unión de las tres principales coronas cristianas del Medioevo peninsular» ${ }^{61}$, aunque consideramos que el motivo de esta obra atiende más bien a una cuestión regionalista. Creemos que tanto la obra finalizada como el boceto son obras cercanas a $1907^{62}$, si las ponemos en relación con «Alzamiento sobre el pavés del primer rey navarro», del Ayuntamiento de Pamplona, fechado en ese año, y con el que presenta bastantes similitudes estilísticas.

Desgraciadamente, el Museo de Navarra sólo cuenta con tres obras del artista que nos ocupa a continuación. Hablamos de Enrique Zubiri (1868-1943), uno de los pintores más influyentes para las generaciones de artistas del siglo xx a través de su importante papel docente en la Escuela de Artes y Oficios de Pamplona ${ }^{63}$. Este artista conjuga en su obra un sobresaliente desarrollo del género paisajístico, que le acompañó a lo largo de toda su vida reproduciendo en diversos soportes los múltiples rincones de la geografía navarra, con una admirable faceta retratística, hasta el punto de que contó durante muchos años con el monopolio del género en la capital navarra obteniendo magníficas críticas. Afortunadamente, el Museo de Navarra cuenta con interesantes ejemplos de ambos géneros. El paisaje queda representado a través de dos lienzos de época diferente, uno de ellos expuesto en la cuarta planta y el otro depositado en el almacén. El más interesante de los dos es el primero, realizado en 1898, que nos ofrece una vista de Pamplona desde la zona extramuros del río Arga a su paso por la capital navarra ${ }^{64}$ (Fig. 5). En primer término, vemos un remanso del río que queda cobijado a un lado por una espesa arboleda, y a otro por un pronunciado terraplén en el que crecen algunos árboles. Sobre las aguas calmadas, y en una pequeña embarcación, un hombre de pie realiza labores de pesca ayudado de una larga caña, mientras que al fondo y a la izquierda se aprecian algunas de las edificaciones del casco antiguo de la ciudad vistas desde el barrio de la Rochapea, zona bastante frecuentada por los artistas navarros de esta generación. Si bien esta obra, de un cromatismo suave y ajustado, puede adscribirse a un grupo de pinturas en las que se advierte la huella madrileña, escapa ligeramente a las entonaciones pardo oscuras propias del momento señaladas por algunos autores ${ }^{65}$. Vemos en ella un concienzudo estudio lumínico y paisajístico que adopta múltiples tonalidades verdosas y doradas que la iluminan agradablemente. Por su parte, el segundo de los paisajes de este artista conservados en el museo, nos muestra una vista de las cumbres de la sierra de Aralar, situada al noroeste de la Comunidad Foral y en cuyo alto se emplaza el santuario de San Miguel, interesante joya del románico navarro ${ }^{66}$. Es obra

\footnotetext{
${ }^{61}$ Reyero, C., La pintura de historia en España. Esplendor de un género en el siglo XIX, Cátedra, Madrid, 1989, p. 112.

${ }^{62}$ Camino Paredes señala que es obra de 1900. Ver Paredes, C., Op. cit., p. 46.

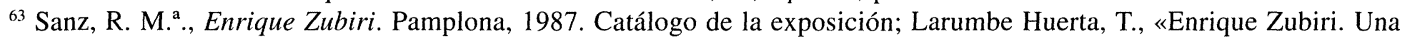
discreta elegancia», en Pintores Navarros, t. I, Pamplona, 1981; Zubiaur, F. J. (1996), 75 años de pintura y escultura en Navarra. 1921-1996, Pamplona, 1996, catálogo de la exposición; Paredes, C., Op. cit.; Alegría Goñi, C., «Pintores contemporáneos I», Op. cit.

64 «Vista de Pamplona», 1898, óleo sobre lienzo, 64 ×91 cms., N. ${ }^{\circ}$ Reg.: 2223. Ingresó en el Museo de Navarra en 1990 junto a «Mendigos», de Ricardo Baroja, del que hablaremos más adelante, 38 dibujos dobre la Guerra Civil de la artista local Francis Bartolozzi, un dibujo con el retrato de Margarita de Navarra atribuido a Clonet, y 10 fotografías de Miguel Bregaza Lambre. Ver Museo de Navarra, Archivo y Biblioteca, Expediente N. ${ }^{\circ} 60,1989$.

${ }^{65}$ Sanz, R. M. ${ }^{a}$., Op. cit.

${ }^{66}$ «Cumbres de Aralar», c.a. 1940-1943, óleo sobre madera, $44 \times 65$ cms., N. ${ }^{\circ}$ Reg.: 2442. Ingresó en el Museo de Navarra en 1991 junto a una acuarela de Bienabe Artía. Ver Museo de Navarra, Archivo y Biblioteca, Registro de entradas, 1991, N. ${ }^{\circ}$ Reg.: 2442.
}

$A E A, \mathrm{LXXV}, 2002,300$, pp. 381 a 396 
en la que predominan los verdes y los marrones que caracterizarán su obra en sus últimos años. Si bien su ficha conservada en el archivo del museo la data de la década de 1880-1890, nosotros creemos que corresponde más bien a su etapa de madurez, en torno a 1940-1943 ${ }^{67}$.

Por su parte, el retrato de Enrique Zubiri expuesto en la cuarta planta junto a la vista de Pamplona representa la efigie de Martín Azpilicueta (Barásoain, 1493-Roma, 1586) ${ }^{68}$, conocido como el doctor navarro, hombre culto, filósofo, teólogo y jurisconsulto ilustre del siglo XVI ${ }^{69}$. Así nos lo aclara un texto en latín situado a la izquierda del retratado: MARTINUS.AB / AZPILICUETA / INSIG.DOCT. / NAVARRUS. Sobre un fondo oscuro, el artista nos presenta un retrato de medio cuerpo, con el efigiado ataviado con toga y birrete negros. A la izquierda presenta el texto señalado y a la derecha el escudo familiar cuartelado en cruz con las distintivas de la familia Azpilicueta ${ }^{70}$. La excelente factura de la obra, de ajustado dibujo, que envuelve al espectador a través de las tonalidades oscuras, con las que se resalta la solemne efigie del retratado, ha sido objeto de numerosos comentarios desde su aparición pública en $1924^{71}$. Aunque la obra no viene fechada, hay autores que la sitúan en el período pamplonés del artista ${ }^{72}$, esto es, tras la etapa formativa en Madrid, y por lo tanto, posterior a 1891, época en la que se convirtió en el retratista oficial de la ciudad, si bien no precisan nada más. Noso-

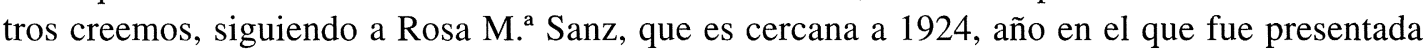
en la capital navarra ${ }^{73}$.

En la cuarta planta, junto a las dos pinturas de Enrique Zubiri, encontramos dos de las cuatro obras de Ricardo Baroja (1871-1953) que se conservan en el Museo de Navarra ${ }^{74}$. Ambas fueron realizadas en 1937 y quedan incluidas dentro de los llamados «croquis de guerra» ${ }^{75}$. Estos croquis comprenden una serie de pinturas hechas por el artista entre 1936 y 1939 en las que quedaron captados diferentes episodios de la contienda civil ${ }^{76}$. El primero de ellos, titulado «Exploradores», nos muestra un paisaje nevado sobre el que se recortan las figuras de cuatro miembros de la Guardia Civil armados y ataviados con tricornio y capuz, avanzando en formación de rastreo. El ambiente frío y desolado del paisaje queda perfectamente plasmado a

${ }^{67}$ En este sentido coincidimos con Rosa María Sanz, quien la data en 1943. Ver Sanz, R. M. a., Op. cit.

${ }^{68}$ «Retrato de Martín Azpilicueta. El doctor navarro», c.a. 1924, óleo sobre lienzo, $75 \times 65$ cms., N. ${ }^{\circ}$ Reg.: 1868 . Ingreso en el Museo en 1982, procedente del Palacio provincial. Ver Museo de Navarra, Archivo y Biblioteca, Registro de entradas, 1982. Ver también Memoria del Museo de Navarra, 1982, p. 6.

${ }^{69}$ Sobre la figura de Martín Azpilicueta, Recondo Iribarren, J. M. ${ }^{a}$, El doctor navarro: Don Martín de Azpilicueta, Temas de Cultura Popular, núm. 112, Pamplona, 1987 (2. ${ }^{a}$ ed.). Para un estudio más extenso, Tejero, E. et alii, Estudios sobre el doctor navarro: En el IV Centenario de la muerte de Martín Azpilicueta, Pamplona, Gobierno de Navarra, 1988.

${ }^{70}$ Erdozáin Gaztelu, A., Linajes en Navarra con Escudos de Armas, vol. I, Pamplona, 1995, pp. 381-385.

${ }^{71}$ Sanz, R. M. ${ }^{\text {. }}$, Op. cit. Ver a este respecto: Esparza, E., «Un cuadro de Zubiri», en La Voz de Navarra, 4 de enero de 1925; Euskaleriaren Alde, enero, 1925, p. 38; «Don Martín Azpilicueta. Cuadro de Zubiri», en Pregón, núm. 2 , 1944. Según un artículo aparecido en la prensa navarra en diciembre de 1924, el artista se valió de «un magnífico busto en alto relieve del Doctor Azpilicueta, representándolo en los últimos años de su vida, que figura en su mausoleo, existente en una de las iglesias de Roma, cuya cabeza es de gran realismo, de rasgos muy originales permiten suponer un acabado parecido con el retratado.» «Un retrato interesante. Don Martín Azpilicueta», en La Voz de Navarra, 28 de diciembre de 1924.

${ }^{72}$ Larumbe Huerta, T., Op. cit., p. 136.

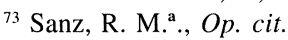

${ }^{74}$ Lafuente Ferrari, E., «Ricardo Baroja y su arte», en Clavileño, núm. 26, 1954; Caro Baroja, J., «El paisaje en la obra de los hermanos Baroja», en Clavileño, núm. 43, 1957; Caro Baroja, P.: «Ricardo Baroja, pintor y grabador», en Pintores y escultores vascos de ayer, hoy y mañana, t. 4, 1973; Álvarez Empananza, J. M. ${ }^{\text {. }, ~ L a ~ p i n t u r a ~ v a s c a, ~ S a n ~ S e b a s t i a ́ n, ~ 1978 ; ~}$ Zubiaur Carreño, F. J., La Escuela del Bidasoa, Pamplona, 1986; Caro Baroja, P.: Imagen y derrotero de Ricardo Baroja, Bilbao, 1987; Paredes, C., Op. cit.; AA.VV, Los Baroja. Memoria y recuerdo, San Sebastián, 1996; AA.VV., Ricardo Baroja y el 98, San Sebastián, 1998.

75 «Exploradores», 1937, óleo sobre tabla, 33,5 × 50 cms., N. ${ }^{\circ}$ Reg.: 2224; y «Nido de ametralladoras», 1937, óleo sobre tabla, 33,5 $\times 50 \mathrm{cms}$., N. ${ }^{\circ}$ Reg.: 2225. Ambas ingresaron en el Museo de Navarra en 1990, ver Registro de entradas, 1990, N. ${ }^{\circ}$ Reg.: 2224 y 2225. Camino Paredes data ambas obras entre 1936 y 1939, si bien ambas viene fechadas en el ángulo inferior izquierdo en 1937. Con esta última fecha las sitúa la guía-catálogo del Museo de Navarra. Ver Paredes, C.: Op. cit., p. 51; y AA.VV.: Guía-catálogo del Museo de Navarra, Pamploa, 1998 (4. a ed.), p. 222.

${ }^{76}$ Caro Baroja, P., Imagen y derrotero..., p. 193. Ver también, Zubiaur Carreño, F. J., La Escuela del Bidasoa..., p. 97. 
través de una pincelada que difumina los contornos, lo que a su vez permite crear la sensación de viento y de perspectiva aérea con gran maestría. Igualmente, la pintura capta la tensión del momento, como si de pronto fuera a iniciarse un tiroteo que rompiera la aparente calma del entorno nevado. Por su parte, el otro cuadro representa un nido de ametralladoras del ejército Nacional en plena contienda civil. Trece personajes se afanan en preparar las armas para el combate, que parece haberse iniciado, parapetados tras una tapia que une dos caserones arruinados por los impactos de los proyectiles. La obra, sin ser de las más crudas que trató el artista sobre esta contienda, transmite la tensión del enfrentamiento fratricida, intensificada por el hecho de no poder ver, más allá del muro de piedra, al otro frente de combate. Estas pinturas, realizadas con técnica impresionista, si bien ésta pasada por una interpretación personal ${ }^{77}$, se presentan a modo de rápidos apuntes de guerra con un importante contenido documental ${ }^{78}$. Pueden ponerse en relación con otras obras de este tipo tales como «Porche de Ayuntamiento», o «Vuelven al Pueblo», ambas del Museo de Bellas Artes de Bilbao ${ }^{79}$.

De diferente temática pero cercana a esta época creemos que es el lienzo titulado «Mendigos», depositado en el almacén del Museo ${ }^{80}$. Se trata de una obra costumbrista muy cercana a la temática de algunos de sus más famosos grabados, en la que el autor ha desarrollado un rico tratamiento cromático, dominado por una luz dorada, muy propia de su última época, que confiere al lienzo un aire nostálgico. El último de los lienzos consiste en un retrato de cuerpo entero de la joven Resurrección Juaristi, hija del cirujano don Victoriano Juaristi, ambos amigos de la familia ${ }^{81}$. Es obra firmada en 1918, ajustada en el dibujo y dominada por los tonos verdes y marrones, aplicados tanto en los vestidos de la joven como en el paisaje del fondo, cuya única nota de color queda dispuesta en la rosa prendida del vestido a la altura del pecho.

El último de los maestros cuyas obras vamos a estudiar es el tudelano Nicolás Esparza (1873-1928), uno de los más interesantes pintores de la nómina y, curiosamente, uno de los menos estudiados ${ }^{82}$. De este interesante pero poco conocido artista se exponen tres obras en la tercera planta. Resultan sumamente sugestivas, ya que nos muestran diversos aspectos de su evolución pictórica desde los años de formación académica en la Escuela Especial de Pintura, Escultura y Grabado de Madrid, hasta sus años de madurez en Sestao, donde alcanzó una gran fama. Su primera etapa está representada por las dos primeras obras, una academia al óleo titulada «Guerrero desnudo» y una escena intimista titulada «Ayudando a la lectura», ambas procedentes del depósito de $1967^{83}$. La primera, firmada en 1894, posiblemente fue enviada por el artista desde Madrid a la Diputación de Navarra durante su tercer (1893-1894) o cuarto (1894-1895) curso académico en los que estuvo matriculado en la asignatura de Dibujo del

\footnotetext{
77 Campoy, A. M., Diccionario crítico de arte español contemporáneo, Madrid, 1973, pp. 50-51; y Álvarez Empananza, J. M. ${ }^{\text {. }}$, La pintura vasca, San Sebastián, 1978, p. 106. Francisco Javier Zubiaur, quien también acepta la influencia impresionista, precisa sobre el asunto señalando que el impresionismo de Ricardo Baroja se encuentra impregnado de un sabor entre romántico y naturalista y sobre todo, que se trata de un impresionismo entendido de forma muy independiente y personal, ver Zubiaur Carreño, F. J., La Escuela del Bidasoa..., p. 99.

${ }^{78}$ Caro Baroja, P., Imagen y derrotero..., p. 195.

${ }^{79}$ «Porche de Ayuntamiento», óleo sobre cartón, $26 \times 37,5$ cm., N. ${ }^{\circ}$ Inv.: 82/79; «Vuelven al pueblo», óleo sobre tabla, 62 ' $5 \times 94^{\prime} 5 \mathrm{~cm}$. Museo de Bellas Artes de Bilbao, N. ${ }^{\circ}$ Inv.: 82/78.

${ }^{80}$ «Mendigos», c.a. 1943-1953, óleo sobre tabla, 49,5 × 66 cms., N. ${ }^{\circ}$ Reg.: 2226. Sobre su ingresó en el Museo de Navarra, ver nota 64 .

${ }^{81}$ Caro Baroja, P., Imagen y derrotero..., pp. 109-111.

${ }^{82}$ Llano Gorostiza, M., Op. cit.; Martín Lomeña, «Nicolás Esparza Pérez. El amor a los demás», en Pintores navarros, t. I, Pamplona, 1981; Gil Gómez, L., Tudelanos notables contemporáneos, en Temas de Cultura Popular, núm. 181, Pamplona, 1984; Paredes, C., Pintores navarros (1850-1940), col. Panorama, núm. 18, Pamplona, 1991; Díez Ochoa, J., Nicolás Esparza 1872-1928, Pamplona, 1991, s/p. Catálogo de la exposición; Alegría Goñi, C., «Pintores contemporáneos I», El Arte en Navarra, t. II, Pamplona, 1994.

${ }^{83}$ «Guerrero desnudo», 1894, óleo sobre lienzo, $84 \times 54$ cms., N. ${ }^{\circ}$ Reg.: 1367 F; «Ayudando a la lectura», 1896, óleo sobre lienzo, $95 \times 77,5 \mathrm{cms}$., N..$^{\circ}$ Reg.: 1367 G, ambas procedentes del depósito de 1967 . Adviértase que en el depósito de 1917 esta obra figuraba como «Estudio de gladiador», ver nota 11.
}

$A E A, \mathrm{LXXV}, 2002,300$, pp. 381 a 396 
natural ${ }^{84}$, recibiendo en las convocatorias de febrero y junio de 1895, correspondientes al cuarto año, sendos diplomas ${ }^{85}$ (Fig. 6). Este lienzo parece ser uno de los trabajos que los artistas pensionados debían enviar a la Diputación que concedía la ayuda para justificar los avances obtenidos en los estudios académicos. El cuadro muestra a un hombre desnudo sobre un fondo blanco, que porta en la mano izquierda un palo largo a modo de lanza, mientras que la derecha se apoya sobre un casco de gladiador depositado sobre una caja cubierta por un tapete marrón. Esta obra puede ponerse en relación con algunos carboncillos de igual temática, como el conservado en el Archivo de la Facultad de Bellas Artes de la Universidad Complutense en el que vemos a un modelo cuyo tipo físico se parece mucho al del cuadro del Museo de Navarra ${ }^{86}$. Quizá se trate de la misma persona que se encargaría de posar para los alumnos de la asignatura de Dibujo del natural en la escuela madrileña.

Dos años más tarde, 1896, está fechada la obra titulada «Ayudando a la lectura» ${ }^{87}$. Se trata de una delicada escena intimista en

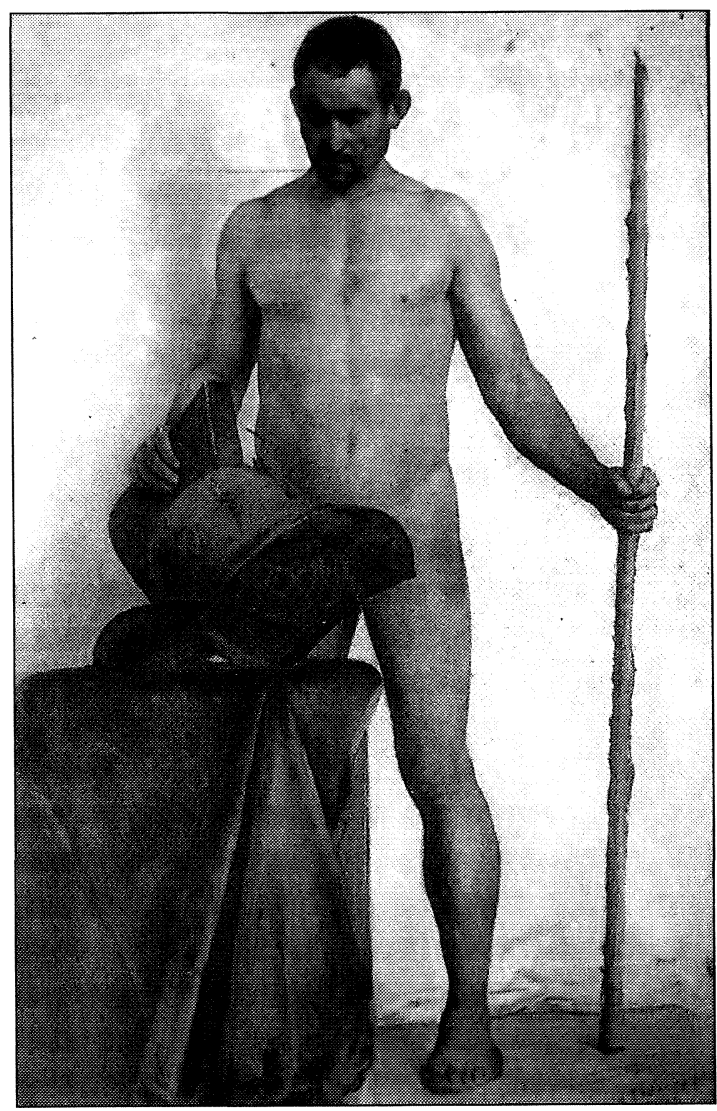

Fig. 6. Nicolás Esparza, Guerrero desnudo, 1894. la que una madre elegantemente vestida ayuda a leer a su hija de un pequeño librito que sostiene entre las manos. La niña, con la mirada fija en el texto, parece esforzarse en seguir las indicaciones que la madre le imparte pacientemente. El delicioso interior de la habitación en la que ambas se encuentran, decorado con papel y telas con motivos vegetales, y bañado por una suave luz procedente de una ventana situada en el margen izquierdo, ayuda a incrementar la sensación de intimidad. Creemos que dicho lienzo tiene un origen similar al «Guerrero desnudo» y que fue enviado por el artista a la Diputación de Navarra en prueba de sus avances en la academia madrileña.

Finalmente, ya de etapa de madurez, encontramos el soberbio retrato de don Manuel María de Alfaro y Morales, realizado en 1919, tal y como figura en el ángulo inferior derecho junto a la firma ${ }^{88}$. El retratado, empresario nacido en Fitero (Navarra) en 1829 y fallecido en $1900^{89}$, que

\footnotetext{
${ }^{84}$ Archivo de la Escuela de Bellas Artes de San Fernando, N. ${ }^{\circ}$ 174-3: Libro de matrículas, fols. 197 vto. y 207.

${ }^{85}$ Ibídem, N. ${ }^{\circ}$ 177-1: Alumnos elegidos al premio de Estudios Superiores, fol. 107 vto.

${ }^{86}$ Los dibujos de la Academia, Madrid, Ed. Universidad Complutense de Madrid, 1990, lámina LXXIII.

${ }^{87}$ Estamos de acuerdo con Emilio Quintanilla, quien considera que esta obra es la que en la documentación de 1917, correspondiente al depósito de obras efectuado por la Diputación en el Museo Arqueológico (ver nota 11), figura con el título de «Estudio de mujer y niña». Ver, Quintanilla, E., Op. cit., p. 274, nota 143.

${ }^{88}$ «Retrato de don Manuel María Alfaro y Morales», 1919, óleo sobre lienzo, 132x99 cms., N. ${ }^{\circ}$ Reg.: 2439. Ingresó en el museo en 1991 si bien en el Registro de entradas de ese año no se especifica la fecha concreta.

${ }^{89}$ Nótese que el retratado falleció en 1900 y sin embargo la obra está fechada en 1919. Esto nos hace pensar que se trata de un retrato post mortem, es decir, realizado tras el fallecimiento del retratado. Algo parecido a lo que hace Zubiri con su retrato del doctor Azpilicueta, aunque reduciendo el enorme abismo temporal que separa al retratado del retrato en esta obra, a tan sólo 19 años. Podemos suponer que Esparza pudo guiarse de alguna fotografía, ayudándose además de la descripción de parientes. Al tratarse de un personaje con cierta relevancia para Fitero, podemos pensar igualmente que este
} 
llegó a ser diputado provincial por el distrito de Tudela, aparece en tres cuartos, de frente, y viste traje de gala con chaqué negro, pantalones grises, camisa de cuello alto que asoma por el pico del chaleco, también negro, corbata, guantes y chistera en la mano izquierda, mientras la derecha descansa con elegancia sobre una mesa. Su imponente presencia resalta ante un fondo neutro que queda iluminado por un halo de luz que rodea su figura. Si en «Guerrero desnudo» hemos podido ver las raíces académicas del artista, y en «Ayudando a la lectura» hemos tenido ocasión de comprobar su capacidad para recrear escenas intimistas, en esta excelente obra queda de manifiesto su sensacional mano para el retrato. No en vano, algunos de los autores califican a Esparza como el retratista más apreciado de Bilbao ${ }^{90}$.

Terminamos aquí este breve estudio sobre las pinturas de la primera generación de maestros navarros que se encuentran en el Museo de Navarra. Creemos que este repaso nos ha permitido precisar algunas cuestiones que hasta ahora o bien se desconocían o bien pecaban de inexactitud. Las obras que hemos examinado son un buen ejemplo del arte en Navarra durante un período tan problemático para la pintura en España como es el correspondiente a su apertura a la modernización, en el que coexisten de un lado las tendencias tradicionales, basadas en los preceptos académicos que se defienden desde los organismos docentes oficiales, con la Academia de San Fernando a la cabeza, y de otro lado, las tendencias más innovadoras, abiertas a las nuevas olas que llegan desde focos europeos a través de centros locales como Barcelona y Bilbao. En medio de este panorama encontramos a los maestros navarros, que si bien estilísticamente se encuentran más arraigados a la corriente tradicional que sensibles a las nuevas tendencias, temáticamente comienzan a interesarse por las nuevas modas.

retrato se realizó a modo de homenaje hacia el efigiado. Una breve reseña biográfica sobre este personaje en García-Sanz Marcotegui, A., Diccionario Biográfico de los Diputados Forales de Navarra, Pamplona, Gobierno de Navarra, 1996, pp. 589-590.

${ }^{90}$ Llano Gorostiza, M., Op. cit., p. 238.

AEA, LXXV, 2002, 300, pp. 381 a 396 